\title{
ANALISIS POTENSI DAN EFEKTIVITAS PENERIMAAN PAJAK RESTORAN DI KOTA TOMOHON
}

\author{
Maria Debora Makalew ${ }^{1}$, Grace B. Nangoi ${ }^{2}$, Robert Lambey ${ }^{3}$ \\ ${ }^{1,2,3}$ Jurusan Akuntansi, Fakultas Ekonomi dan Bisnis, Universitas Sam Ratulangi, Jl. Kampus Bahu, Manado, \\ 95115, Indonesia \\ E-mail : mariamakalew14@gmail.com
}

\begin{abstract}
Restaurant tax is one of the solutions to increase local revenues, since one of the region's largest indigenous revenues is contributed by taxes in the City of Tomohon. The purpose of this research is to know the potential and effectiveness of restaurant tax in Tomohon City. The result showed that the realization of restaurant tax obtained exceeds the target of restaurant tax that has been set but the target tax restaurant has a very far difference from the potential tax restaurant. This is evidenced by the calculation of the difference between the target of restaurant tax receipts to the potential of restaurant tax revenues. The level of tax effectiveness of Tomohon City restaurant is fiscal year 2013-2016 is considered "very effective". It can be seen from the realization of tax revenue every year that exceeds the target of tax revenue. The result of the research can be concluded that, the tax revenue of restaurants in Tomohon City has been very effective but it does not reflect the actual potential, therefor the Regional Finance Agency of Tomohon should optimize the income of restaurant tax in order to increase the local revenue.
\end{abstract}

Keywords : Restaurant Tax, Admission Potential, Effectiveness

\section{PENDAHULUAN}

Indonesia merupakan negara yang menjadikan pajak sebagai sumber penerimaan utama negara dalam melaksanakan tugas pemerintahan dan pembangunan. Pajak menjadi kewajiban yang harus dibayar oleh setiap wajib pajak, yang akan dikelola oleh negara atau daerah. Tanpa pajak, pembangunan nasional maupun pembangunan daerah tidak akan berjalan dengan lancar. Hal ini dikarenakan, banyak kegiatan negara maupun daerah yang sangat bergantung pada penerimaan yang berasal dari pajak. Pajak restoran seharusnya cukup potensial untuk mempengaruhi peningkatan pendapatan asli daerah Kota Tomohon seiring dengan semakin pesatnya pertumbuhan perusahaan atau industri dan pariwisata akan meningkatkan pendapatan asli daerah melalui pajak restoran. Pajak restoran sebagai salah satu sumber pendapatan daerah yang berpotensi perlu dilakukan pemungutan secara efisien, efektif, dan ekonomis sehingga dapat lebih berperan dalam usaha peningkatan Pendapatan Asli Daerah di Kota Tomohon. Oleh karena itu untuk mengoptimalkan pengelolaan pajak restoran maka diperlukan adanya sebuah perencanaan, pengorganisasian, penggerakan serta pengawasan yang baik oleh Pemerintah Kota Tomohon khususnya bagi Badan Keuangan Daerah dalam hal pemungutan Pajak Restoran. Apabila semakin baik pemungutan pajak restoran di wilayah kabupaten/kota, maka semakin optimal pula pendapatan asli daerah dari sektor pajak. 


\section{TINJAUAN PUSTAKA}

\subsection{Konsep Akuntansi}

Akuntansi adalah aktivitas mengumpulkan, menganalisis, menyajikan, dalam bentuk angka, mengklasifikasikan, mencatat, meringkas, dan melaporkan aktivitas/transaksi perusahaan dalam bentuk informasi keuangan (Rudianto, 2012:16).

\subsection{Konsep Pajak}

\subsubsection{Pengertian Pajak}

Menurut Andriani dalam Sari (2013:34), "pajak adalah iuran masyarakat kepada negara (yang dapat dipaksakan) yang terutang oleh yang wajib membayarnya menurut peraturan-peraturan umum (undang-undang) dengan tidak mendapatkan prestasi kembali yang langsung dapat ditunjuk dan yang gunanya adalah untuk membiayai pengeluaranpengeluaran umum berhubung tugas negara untuk menyelenggarakan pemerintahan". Menurut Soemitro dalam Sari (2013:34), "pajak adalah iuran rakyat kepada kas negara berdasarkan undang-undang (yang dapat dipaksakan) dengan tiada mendapat jasa timbal balik (kontraprestasi) yang langsung dapat ditunjukan dan yang digunakan untuk membayar pengeluaran umum".

\subsubsection{Asas-asas Pemungutan Pajak}

Menurut Adam Smith dalam Suandy (2011:25), asas-asas pemungutan pajak yang dikenal dengan nama four cannons atau the four maxims dapat dikelompokkan sebagai berikut:
1. Equality
2. Certainty
3. Convenience of payment
4. Economy of collections

\subsubsection{Fungsi Pajak}

Menurut Mardiasmo (2011:1-2), ada dua fungsi pajak, yaitu:

1. Fungsi Budgetair

2. $\quad$ Fungsi Mengatur (Regulerend)

\subsubsection{Syarat Pemungutan Pajak}

Agar pemungutan pajak tidak menimbulkan hambatan, maka pemungutan pajak harus memenuhi syarat sebagai berikut (Mardiasmo, 2011:2):

1. Pemungutan pajak harus adil (Syarat Keadilan)

2. Pemungutan pajak harus berdasarkan Undang-Undang (Syarat Yuridis)

3. Tidak mengganggu perekonomian (Syarat Ekonomis)

4. Pemungutan pajak harus efisien (Syarat Finansial)

5. Sistem pemungutan pajak harus sederhana

\subsubsection{Pengelompokan Pajak}

Sari (2013:43) membagi pengelompokan pajak menurut golongannya sebagai berikut:

1. Menurut Pembebanan-nya

a. Pajak langsung

b. Pajak tidak langsung

2. Menurut Sifat-nya
a. Pajak Subjektif
b. Pajak Objektif

3. Menurut Kewenangan-nya
a. Pajak Pusat
b. Pajak Daerah

\subsubsection{Tata Cara Pemungutan Pajak}

1. Stelsel Pajak 
Pemungutan pajak dapat dilakukan berdasarkan 3 stelsel (Mardiasmo, 2011:67) yaitu:

a. Stelsel Nyata (Riel Stelsel)

b. Stelsel Anggapan (Fictieve Stelsel)

c. Stelsel Campuran

2. Sistem Pemungutan Pajak

a. Official Assessment System

b. Self Assessment System

c. With Holding System

\subsubsection{Tarif Pajak}

Menurut Adam Smith dalam Sari (2013:46), ada dua prinsip keadilan, yaitu:

1. Benefit principle

2. Ability to pay

\subsubsection{Teori Pemungutan Pajak}

Hukum pajak harus berdasarkan keadilan dan untuk menyatakan keadilan kepada hak negara untuk memungut pajak, ada beberapa teori dasar pemungutan pajak menurut Sari (2013:75), yaitu:

1. Teori Asuransi

2. Teori Kepentingan

3. Teori Daya Pikul

4. Teori Bakti

5. Teori Daya Beli

\subsection{Pajak Daerah}

Pajak daerah menurut Siahaan (2013:9), adalah iuran wajib yang dilakukan oleh daerah kepada orang pribadi atau badan tanpa imbalan langsung yang seimbang, yang dapat dipaksakan berdasarkan peraturan perundang-undangan yang berlaku, yang digunakan untuk membiayai penyelenggaraaan pemerintah daerah dan pembangunan daerah.

Menurut Davey dalam Surbakti (2014:213), pemerintah daerah dapat memperoleh penerimaan pajak melalui tiga sumber: bagi hasil pajak yang dikenakan dan dipungut oleh pemerintah pusat; tambahan pajak yang dipungut oleh pemerintah daerah di atas pajak yang dipungut dan dikumpulkan oleh pemerintah pusat; pajak yang dikumpulkan dan ditahan oleh pemerintah daerah sendiri. Untuk sumber yang ketiga, yaitu pajak yang dipungut oleh pemerintah daerah harus memiliki dasar hukum sebagai kewenangannya. Dasar hukum dapat ditetapkan berdasarkan peraturan dari pemerintah pusat. Namun, ada juga pajak daerah yang dikenakan oleh pemerintah daerah berdasarkan peraturan-perundangan daerah.

\subsection{Pajak Restoran}

Pajak Restoran adalah pajak atas pelayanan yang disediakan oleh restoran. Restoran adalah fasilitas penyedia makanan dan/atau minuman dengan dipungut bayaran, yang mencakup juga rumah makan, kafetaria, kantin, warung, bar, dan sejenisnya termasuk jasa boga/katering.

\section{METODE PENELITIAN}

\subsection{Jenis Penelitian}

a. Data kualitatif adalah data yang disajikan dalam bentuk kata-kata yang mengandung makna dan tidak dapat dikuantitatifkan. Jenis data seperti ini berupa sejarah singkat perusahaan, struktur organisasi, dan informasi lainnya yang relevan dengan penulisan ini.

b. Data kuantitatif adalah data yang berupa angka-angka. Jenis data seperti ini berupa data yang berhubungan target dan realisasi pajak restoran di Kota Tomohon. 


\subsection{Tempat dan Waktu Penelitian}

Penelitan ini lakukan pada Badan Keuangan Daerah Kota Tomohon yang bertempat di kelurahan Kolongan, Kecamatan Tomohon Tengah, Kota Tomohon. Waktu penelitian dilakukan pada 12 September 2017-13 Oktober 2017.

\subsection{Prosedur Penelitian}

Langkah-langkah prosedur dalam penelitian, yaitu sebagai berikut:

1. Melakukan kajian awal dengan melakukan studi literatur baik studi kepustakaan maupun membaca melalui internet.

2. Melakukan pengidentifikasian tentang masalah, merumuskannya, menetapkan tujuan/manfaat penelitian.

3. Membatasi masalah ke lingkup yang disesuaikan dengan penelitian saat ini.

4. Perancangan dan persiapan survei pada objek penelitian yang telah ditentukan.

5. Pengumpulan data baik primer maupun sekunder.

6. Melakukan pengolahan data, membahasnya kemudian menarik kesimpulan dan memberikan saran-saran guna melengkapi penelitian.

\subsection{Metode Pengumpulan Data}

Metode analisis yang digunakan dalam penelitian ini adalah metode analisis deskriptif kuantitatif. Penelitian secara deskriptif adalah penelitian yang meliputi pengumpulan data untuk diuji hipotesis atau menjawab status terakhir dari subyek penelitian. (Kuncoro, 2004)

Menurut Muhammad (2009) penelitian kuantitatif adalah penelitian dengan menggunakan model matematis, statistik, atau komputer. Jadi, metode deskriptif kuantitatif bertujuan untuk menggambarkan dan mengungkapkan suatu masalah, keadaan, peristiwa sebagaimana adanya.

\subsection{Metode Analisis}

1. Potensi Pajak Restoran ini diperoleh dengan cara mengalikan jumlah pengunjung yang datang ke restoran, harga rata-rata makanan dan minuman yang dijual, jumlah hari dalam satu tahun (365 hari), dan tarif yang ditetapkan oleh pemerintah.

Potensi Pajak Restoran $=$ Jumlah pengunjung $x$ Harga makanan rata-rata $x 365 \times 10 \%$

2. Untuk menghitung efektivitas pengelolaan Pajak Restoran digunakan rumus sebagai berikut:

$$
\text { Efektifitas }=\frac{\text { Realisasi penerimaan pajak }}{\text { Target penerimaan pajak }} \times 100 \%
$$

\section{HASIL ANALISIS DAN PEMBAHASAN}

4.1 Hasil Penelitian dan Analisis

\subsubsection{Potensi Penerimaan Pajak Restoran}

Untuk menghitung potensi penerimaan Pajak Restoran digunakan rumus:

Potensi Pajak Restoran $=$ Jumlah Pengunjung Rata-rata $\mathbf{x}$ Harga Makanan Rata-rata $\mathbf{x}$ $300 \times 10 \%$

1. Jumlah Restoran dan Rumah Makan di Kota Tomohon 
Tabel 4.1 Data Wajib Pajak Restoran/Rumah Makan di Kota Tomohon

\begin{tabular}{|c|c|}
\hline RESTORAN & KEC. TOMOHON UTARA \\
\hline $\begin{array}{l}\text { RM. SRI WEDARI } \\
\text { RM. KAPUNG KODO / SERUNI } \\
\text { RM. EKONOMI I / SURIMAN } \\
\text { RM. EKONOMI I / IRWAN / Talete } \\
\text { RM. EKONOMI III / DEWI / Kolongan } \\
\text { KFC (RESTORAN) } \\
\text { RM. BATAGOR / MATANI } \\
\text { RM. MEGFRAH } \\
\text { RM. SELERA PADANG } \\
\text { RM. HONGKONG } \\
\text { RM. PARAKLETOS / MATANI } \\
\text { RM. MANGGARAI } \\
\text { RM. SARI RASA } \\
\text { RM. PUTERI SOLO / MATANI II } \\
\text { RM. THE SPRING } \\
\text { RM. SUPER STAR } \\
\text { RM. ARAFAH } \\
\text { RM. SUDI MAMPIR } \\
\text { RM. BAKSO MAS MUL } \\
\text { RM. KITSANG } \\
\text { RM. TAMBALA } \\
\text { RM. KIOS KARNO } \\
\text { RM. TOMARU CAFÉ } \\
\text { RM. 69 } \\
\text { RM. NEW RAJA LAUT } \\
\text { RM. THE ROG'S } \\
\text { RM. SINELEYAN } \\
\text { RM. BAKSO MAS SUGI } \\
\text { RM. KRENDANG 1 } \\
\text { RM. KRENDANG } 2 \\
\text { RM. BAKSO SURABAYA } \\
\text { RM. LOBA KANAKA } \\
\text { RM. CORRY } \\
\text { RM. RANTAU MINANG } \\
\text { RM. DANDY'S } \\
\text { RM. D’TUNA } \\
\text { RM. PEI FANG } \\
\text { RM. BETANIA } \\
\text { RM. BAKSO SOLO PAK EKO } \\
\text { RM. DABU-DABU LILANG } \\
\text { RM. GALILEA } \\
\text { RM. HRV } \\
\text { RM. BAKMI AKIM } \\
\text { RALALA }\end{array}$ & $\begin{array}{l}\text { RM. TAMISCO } \\
\text { RM. TINOOR JAYA } \\
\text { RM. PEMANDANGAN } \\
\text { RM. HENG MIEN } \\
\text { RM. RIZOMA } \\
\text { RM. PARAKLETOS } \\
\text { RM. GARDENIA } \\
\text { RM. ABI } \\
\text { RM. CITRA } \\
\text { RM GREEN GARDEN } \\
\text { RM. INSPIRASI } \\
\text { RM. VITA NOVA } \\
\text { RM. OKOY FLOWER GARDEN } \\
\text { RM. KANZO } \\
\text { RM. CHI-CHI } \\
\text { RM. MTV } \\
\text { RM. VON-VON } \\
\text { RM. BALI HOUSE } \\
\text { RM. HOUSE OF KITTY (KAKASKASEN) } \\
\text { RM. HOCKY } \\
\text { RM. BUKIT DOA } \\
\text { RM. BIBIR IKAN OM GODE } \\
\text { BAKSO SOLO (RESTORAN) } \\
\text { RM. CERIA PAK EKO } \\
\text { RM. RANTAU MINANG } \\
\text { RM. CAHAYA TINOOR } \\
\text { RM. TERASA } \\
\text { RM. HOK LAE } \\
\text { RM. DIANI } \\
\text { RM. 5R \& 21 } \\
\text { KEC. TOMOHON TIMUR } \\
\text { RM. ANUGERAH } \\
\text { RM. BAKSO NUSANTARA } \\
\text { RM. 89 } \\
\text { RM. MTV } \\
\text { RM. COTTO RAHMAN } \\
\text { RM. BAKSO SAMIDO } \\
\text { RM. KIOS BAKSO BERIMAN } \\
\text { RM. BAKSO PODO MARO } \\
\text { RM. BAKSO MUCHTAR } \\
\text { RM. KEDAI BAHSO } \\
\text { KEC. TOMOHON SELATAN } \\
\text { RM. MENTARI } \\
\text { RM. SECRET } 7 \\
\text { RM. MAS TOPAN } \\
\text { RM. D'LINOW } \\
\text { RM. AN NUR } \\
\text { RESTO THE SPRING (RESTORAN) } \\
\text { RM. KOBONG KAFE } \\
\text { RM. PINUS LAHENDONG } \\
\text { RM. BAKSO PAK EKO } \\
\text { RM. UNIK }\end{array}$ \\
\hline
\end{tabular}

Sumber: Badan Keuangan Daerah Kota Tomohon 
2. Menentukan Sampel

Diambil sampel untuk restoran yaitu Bakso Solo dan untuk rumah makan yaitu RM. Bakso Surabaya

3. Melakukan Observasi

a. Bakso Solo

- Harga rata-rata makanan dan minuman $=$ Rp45.000

- Jumlah pengunjung rata-rata perhari $=35$

b. RM. Bakso Surabaya

- Harga rata-rata makanan dan minuman $=\mathrm{Rp} 30.000$

- Jumlah pengunjung rata-rata perhari $=55$

4. Menghitung Potensi Penerimaan Pajak Restoran

a. 35 X Rp45.000 X 300 X $10 \%$

$=\mathrm{Rp} 47.250 .000$

Ada 3 buah restoran, jadi potensi pajaknya

$=3$ X Rp47.250.000

$=\mathrm{Rp} 141.750 .000$

b. 55 X Rp30.000 X $300 \times 10 \%$

$=\mathrm{Rp} 49.500 .000$

Ada 90 buah rumah makan, jadi potensi pajaknya

$=90 \times$ Rp49.500.000

$=\mathrm{Rp} 4.455 .000 .000$

Jadi potensi penerimaan Pajak Restoran adalah

$=\mathrm{Rp} 141.750 .000+\mathrm{Rp} 4.455 .000 .000$

$=\mathrm{Rp} 4.596 .750 .000$

Berdasarkan hasil penelitian dan perhitungan potensi, total potensi penerimaan Pajak Restoran di Kota Tomohon adalah sebesar Rp4.596.750.000. Potensi penerimaan Pajak Restoran dihitung dari total potensi penerimaan Pajak Restoran dan Pajak Rumah Makan yang menjadi wajib pajak di Kota Tomohon. Dari jumlah total potensi Pajak Restoran dan Pajak Rumah Makan, jumlah potensi Rumah Makan lebih tinggi sebesar Rp4.455.000.000 dari jumlah potensi Restoran hanya sebesar Rp141.750.000. Besarnya jumlah potensi itu dilihat dari jumlah wajib pajak rumah makan lebih banyak dari jumlah wajib pajak restoran dengan jumlah rumah makan 90 buah dan jumlah restoran 3 buah.

\subsubsection{Efektivitas Penerimaan Pajak Restoran}

Tabel 4.2 Efektivitas Penerimaan Pajak Restoran Kota Tomohon

\begin{tabular}{cccccc}
\hline No. & $\begin{array}{c}\text { Tahun } \\
\text { Anggaran }\end{array}$ & Target $(\mathbf{R p )}$ & $\begin{array}{c}\text { Realisasi } \\
(\mathbf{R p})\end{array}$ & $\begin{array}{c}\text { Presentas } \\
\mathbf{e}(\boldsymbol{\%})\end{array}$ & $\begin{array}{c}\text { Kriteria } \\
\text { Efektivitas }\end{array}$ \\
\hline $\mathbf{1}$ & 2013 & 1.175 .000 .000 & 1.484 .959 .553 & 126,38 & Sangat Efektif \\
$\mathbf{2}$ & 2014 & 1.289 .600 .000 & 2.140 .442 .860 & 165,98 & Sangat Efektif \\
$\mathbf{3}$ & 2015 & 1.858 .600 .000 & 3.019 .391 .763 & 162,46 & Sangat Efektif \\
$\mathbf{4}$ & 2016 & 3.087 .232 .000 & 3.451 .597 .137 & 111,8 & Sangat Efektif \\
\hline
\end{tabular}

Sumber: Badan Keuangan Daerah Kota Tomohon (data olahan 2017)

1. Tahun 2013

$$
\begin{aligned}
\text { Efektifitas } & =\frac{1.484 .959 .553}{1.175 .000 .000} \times 100 \% \\
& =126,38 \%
\end{aligned}
$$


2. Tahun 2014

$$
\begin{aligned}
\text { Efektifitas } & =\frac{1.289 .600 .000}{2.140 .442 .860} \times 100 \% \\
& =165,98 \%
\end{aligned}
$$

3. Tahun 2015

$$
\begin{aligned}
\text { Efektifitas } & =\frac{1.858 .600 .000}{3.019 .391 .763} \times 100 \% \\
& =162,46 \%
\end{aligned}
$$

4. Tahun 2016

$$
\begin{aligned}
\text { Efektifitas } & =\frac{3.087 .232 .000}{3.451 .597 .137} \times 100 \% \\
& =111,80 \%
\end{aligned}
$$

Berdasarkan penghitungan dapat dilihat tingkat efektivitas pajak restoran untuk tahun anggaran 2013-2016 penerimaan pajak restoran melebihi target yang ditetapkan pemerintah, sehingga tingkat efektivitas pajak restoran tahun anggaran 2013-2016 di Kota Tomohon dapat digolongkan "Sangat Efektif" dengan persentase tingkat kenaikan yaitu 126,38\% pada tahun 2013, 165,98\% pada tahun 2014, 162,46\% pada tahun 2015, dan 111,8\% pada 2016.

\subsection{Pembahasan}

\subsubsection{Analisis Potensi Pajak Restoran}

Hasil Tabel 3 menggambarkan bahwa realisasi pajak restoran yang didapat melebihi target pajak restoran yang sudah ditetapkan akan tetapi target pajak restoran tersebut mempunyai selisih yang sangat jauh dari potensi pajak restoran.

Ini terjadi karena beberapa atau mungkin sebagian besar dari para pelaku usaha-usaha restoran yang ada di Kota Tomohon kurang memahami tentang peraturan daerah mengenai besarnya pajak restoran yang harus dipungut, dengan kata lain pajak yang dibayarkan tidak sesuai dari yang seharusnya dan pihak pemerintah sendiri kurang menekan para pelaku usaha yang ada di Kota Tomohon untuk taat membayar pajak sebesar yang seharusnya. Serta pihak pemerintah Kota Tomohon khususnya Badan Keuangan Daerah Kota Tomohon seharusnya membuat suatu sistem yang mempunyai tujuan adanya keterbukaan informasi dari pihak wajib pajak restoran kepada publik maupun pemerintah sendiri. Jika semua pihak-pihak yang berkaitan langsung dengan pajak restoran ini sudah memperbaiki sistem dan pelayanan maka potensi pajak restoran akan terealisasi dengan baik.

Seharusnya, penerimaan pajak restoran di kota Tomohon dapat lebih besar lagi, apabila pemerintah menetapkan objek pajak restoran yang lainnya, seperti kafetaria, kantin, warung, depot, bar, pujasera/food court, toko roti/bakery, jasa boga/katering (yang penjualannya tidak melebihi satu juta rupiah setiap tahun), yang sudah ada di kota Tomohon tetapi pemerintah belum menetapkannya sebagai objek pajak restoran.

Apabila pemerintah menetapkan sebagai objek pajak, maka penerimaan pajak restoran di Kota Tomohon akan semakin naik, dan dengan itu pajak daerah dan PAD akan lebih besar lagi. Jika PAD semakin besar, maka kemungkinan masyarakat akan sejahtera akan lebih besar pula. 


\subsubsection{Analisis Efektivitas Pajak Restoran}

Tabel 4.3 Efektivitas Penerimaan Pajak Restoran Kota Tomohon (Review)

\begin{tabular}{cccccc}
\hline No. & $\begin{array}{c}\text { Tahun } \\
\text { Anggaran }\end{array}$ & Target (Rp) & Realisasi (Rp) & $\begin{array}{c}\text { Presentase } \\
(\%)\end{array}$ & $\begin{array}{c}\text { Kriteria } \\
\text { Efektivitas }\end{array}$ \\
\hline 1 & 2013 & 1.175 .000 .000 & 1.484 .959 .553 & 126,38 & Sangat Efektif \\
2 & 2014 & 1.289 .600 .000 & 2.140 .442 .860 & 165,98 & Sangat Efektif \\
3 & 2015 & 1.858 .600 .000 & 3.019 .391 .763 & 162,46 & Sangat Efektif \\
4 & 2016 & 3.087 .232 .000 & 3.451 .597 .137 & 111,8 & Sangat Efektif \\
\hline
\end{tabular}

Sumber: Badan Keuangan Daerah Kota Tomohon (data olahan 2017)

Berdasarkan tabel 4.3 dapat dilihat tingkat efektivitas pajak restoran untuk tahun anggaran 2013-2016 penerimaan pajak restoran melebihi target yang ditetapkan pemerintah, sehingga tingkat efektivitas pajak restoran tahun anggaran 2013-2016 di Kota Tomohon dapat digolongkan "Sangat Efektif". Pada tahun 2013 terget pajak restoran yang ditetapkan pemerintah yaitu sebesar Rp.1.175.000.000 dan terealisasi baik dengan penerimaan sebesar Rp1.484.959.553 persentase 126,38\% “sangat efektif”, pada tahun 2014 target pajak restoran yang ditetapkan pemerintah sebesar Rp1.289.600.000 dan terealisasi dengan baik bahkan mengalami peningkatan penerimaan sebesar Rp2.140.442.860 persentase 165,98\% "sangat efektif", pada tahun 2015 target pajak restoran yang ditetapkan pemerintah sebesar Rp1.858.600.000 dan terealisasi dengan baik dengan penerimaan sebesar Rp3.019.391.763 persentase 162,46\% "sangat efektif", dan pada tahun 2016 pemerintah menaikkan target pajak restoran menjadi Rp3.087.232.000 dan terealisasi dengan baik dengan penerimaan sebesar Rp3.451.597.137 persentase 111,8\% "sangat efektif".

Peneliti mengambil kesimpulan bahwa tingkat efektifitas pemungutan Pajak Restoran menunjukkan progress yang baik. Hal ini di karenakan upaya pemerintah dalam meningkatkan penerimaan Pajak Restoran agar efektivitas pajak dapat lebih efektif sudah dilaksanakan dengan baik. Upaya-upaya yang ditempuh Pemerintah Kota Tomohon, untuk meningkatkan penerimaan pajak restoran dilakukan dengan cara Intensifikasi dan Ekstensifikasi Pendapatan Asli Daerah. Dengan upaya-upaya pemerintah Kota Tomohon dalam hal ini Badan Keuangan Daerah Kota Tomohon, maka penerimaan pajak daerah khusunya pajak restoran mengalami peningkatan setiap tahunnya. Namun pemerintah masih memiliki hambatan atau kendala dalam pemugutan pajak sehingga penerimaan pajak belum maksimal. Hambatan-hambatan Badan Keuangan Daerah dalam pemungutan pajak restoran yaitu:

1. Masih kurangnya kesadaran masyarakat dalam hal ini wajib pajak untuk mendaftarkan dan membayar pajak merupakan kendala utama dalam proses pemungutan pajak, hal tersebut dikarenakan informasi yang diberikan oleh pihak pemerintah kepada wajib pajak masih sangat kurang.

2. Volume pekerjaan yang begitu banyak namun tidak dibarengi dengan jumlah pegawai yang memadai. Kurangnya sumber daya manusia, yaitu jumlah PDL (pegawai dinas luar) yang masih terbatas untuk melakukan pendataan dan penagihan kepada wajib pajak yang hanya berjumlah 8 orang, jika dibandingkan dengan kota lain seperti Kota Bitung jumlah PDL mencapai 60 orang.

3. Kurangnya sanksi yang tegas dari pihak pemerintah terhadap wajib pajak yang tidak patuh dalam hal membayar pajak. 


\section{KESIMPULAN DAN SARAN}

\subsection{Kesimpulan}

Berdasarkan hasil penelitian dan pembahasan pada bab sebelumnya, maka dapat ditarik kesimpulan yaitu sebagai berikut:

1. Potensi Pajak Restoran di Kota Tomohon cukup tinggi, dapat dilihat dari perhitungan potensinya, itu berarti pendapatan pajak daerah pada sektor Pajak Restoran dapat meningkatkan PAD melalui sektor Pajak Daerah.

2. Tingkat efektivitas Pajak Restoran Kota Tomohon pada tahun anggaran 2013-2016 dinilai "sangat efektif". Dapat dilihat dari realisasi penerimaan pajak setiap tahunnya yang melebihi target penerimaan pajak.

3. Upaya-upaya yang ditempuh Pemerintah Kota Tomohon, untuk meningkatkan penerimaan pajak restoran yaitu dilakukan dengan cara Intensifikasi dan Ekstensifikasi Pendapatan Asli Daerah.

\subsection{Saran}

Dilihat dari potensi dan efektivitas penerimaan pajak restoran, pemerintah Kota Tomohon masih memiliki hambatan-hambatan dalam proses pemungutan pajak. Saran penulis untuk Badan Keuangan Daerah adalah sebagai berikut:

1. Melakukan penyuluhan atau sosialisasi yang lebih intensif lagi kepada wajib pajak khususnya dan masyarakat pada umumnya, sosialisasi bisa dilakukan dengan cara himbauan melaui siaran radio atau televisi ataupun menggunakan spanduk atau poster, dan lain-lain, agar masyarakat dan wajib pajak mempunyai tanggung jawab untuk melaporkan data secara jujur dan berperan aktif dalam mendaftarkan objek pajaknya, tidak hanya bergantung pada pemerintah yang terkait.

2. Memberikan sanksi tegas kepada wajib pajak yang tidak memenuhi kewajiban perpajakan sebagaimana mestinya sehingga segala bentuk kecurangan bisa diminimalkan dan pemungutan pajak bisa dilaksanakan secara optimal.

3. Melakukan rekruitmen pegawai untuk menambah jumlah staf Badan Keuangan Daerah Kota Tomohon, serta meningkatkan kualitas dan profesionalisme sumber daya aparatur pengelola pajak sehingga penerimaan pajak bisa optimal, seperti mengikutsertakan aparatnya dalam program-program pendidikan dan pelatihan yang berkaitan dengan pengelolaan daerah.

4. Menambah jumlah sarana prasarana perlengkapan kantor pada Badan Keuangan Daerah seperti meja dan kursi yang sesuai dengan jumlah staf. Serta pengadaan mesin penghitung uang untuk menghitung jumlah pembayaran pajak sehingga pembayaran pajak dapat dilakukan dengan cepat dan tepat.

5. Mencari objek-objek pajak restoran yang baru yang dapat dikenakan pajak, yang objek-objek ini pada waktu yang lalu tidak dikenakan pajak.

6. Kontrol Pemerintah terhadap instansi terkait lebih ditingkatkan lagi agar tercipta kinerja yang baik sehingga tahun-tahun selanjutnya dapat memberikan hasil yang memuaskan.

\section{DAFTAR PUSTAKA}

Arni, Muhammad. 2009. Komunikasi Organisasi. Jakarta: Bumi Aksara.

Ambrosius Frangki Tampi. 2011. Analisis Potensi, Efisiensi dan Efektivitas Penerimaan Pajak Restoran di Kota Bitung. Fakultas Ekonomi dan Bisnis Universitas Sam Ratulangi Manado.

Aprianto Pangloli. 2015. Analisis Potensi Pajak Penerangan Jalan Terhadap Pendapatan Asli Daerah di Kabupaten Tana Toraja. Fakultas Ekonomi dan Bisnis Universitas Hasanuddin Makassar. 
Aristanti Widyaningsih. 2009. Analisa Potensi Penerimaan Pajak Reklame Kota Bandung Periode Tahun 2001-2007. Universitas Pendidikan Indonesia.

Betty Rahayu. 2011. Analisis Potensi Pajak Hotel Terhadap Realisasi Penerimaan Pajak Hotel di Kabupaten Gunungkidul. Fakultas Ekonomi Universitas Diponegoro Semarang.

Chlief Watuseke, Sifrid S. Pangemanan. 2015. Analisis Potensi Pajak Hiburan di Kota Manado. Fakultas Ekonomi dan Bisnis Universitas Sam Ratulangi Manado.

Dewi Mentari, Sri Rahayu. 2015. Efektivitas dan Kontribusi Penerimaan Pajak Hotel dan Pajak Restoran terhadap Pendapatan Asli Daerah (Studi Kasus pada Pemerintah Daerah Kota Bandung Tahun Anggaran 2009-2013). Fakultas Ekonomi dan Bisnis Universitas Telkom.

Diaz Ardhiansyah, Sri Mangesti Rahayu, Achmad Husaini. 2014. Analisis Potensi Pajak Hotel dan Pajak Restoran dan Kontribusinya Terhadap Pendapatan Asli Daerah (PAD) (studi Kasus pada Dinas Pendapatan Daerah Kota Batu Tahun 2011-2013). Fakultas Ilmu Administrasi Universitas Brawijaya Malang.

Garry A. G. Dotulong, David P. E. Saerang, Agus T. Poputra. 2014. Analisis Potensi Penerimaan dan Efektivitas Pajak Restoran di Kabupaten Minahasa Utara. Fakultas Ekonomi dan Bisnis Universitas Sam Ratulangi Manado.

Hamrolie, H. 2003. Menghitung Potensi Pajak dan Retribusi Daerah. Jakarta: BPFE.

Harahap, Sofyan Safri. 2012. Teori Akuntansi, Edisi Revisi. Jakarta: PT. Raja Grafindo.

Irma Sulistiani Rusdy. 2014. Analisis Potensi Pajak Reklame Terhadap Pendapatan Asli

Daerah di Kota Makassar. Fakultas Ekonomi dan Bisnis Universitas Hasanuddin Makassar.

Kuncoro, Mudrajat. 2004. Otonomi dan Pembangunan Daerah. Erlangga: Jakarta.

Mardiasmo. 2011. Perpajakan (Edisi Revisi 2011). Yogyakarta: CV. Andi Offset.

Nazir, M. 2011. Metode Penelitian. Bogor: Ghalia Indonesia.

Ni Kadek Ari Riastini, Ni Kadek Sinarwati, I Putu Gede Diatmika. 2017. Efektivitas dan

Kontribusi Pajak Hotel dan Restoran di Kitamani Terhadap Pandapatan Asli Daerah

Kabupaten Bangli Tahun 2011-2015. Universitas Pendidikan Ganesha Singaraja.

Rezlyanti Kobandaha, Heince R. N. Wokas. 2016. Analisis Efektivitas, Kontribusi dan Potensi Pajak Reklame dan Pajak Hotel Terhadap Asli Daerah Kota Kotamobagu. Fakultas Ekonomi dan Bisnis Universitas Sam Ratulangi Manado.

Rian Frans Samuel Kaparang. 2011. Analisis Potensi Penerimaan dan Efektivitas Pemungutan Pajak Penerangan Jalan di Kota Manado. Fakultas Ekonomi dan Bisnis Universitas Sam Ratulangi Manado.

Rudianto. 2012. Akuntansi Pengantar. Jakarta: Penerbit Erlangga.

Sari, Diana. 2013. Konsep Dasar Perpajakan. Bandung: PT. Refika Aditama.

Siahaan, Mariot Palaha. 2013. Pajak Daerah \& Retribusi Daerah. Jakarta: PT. Rajarafindo Persada.

Simanjuntak, Payaman J. 2003. Produktivitas Kerja Pengertian dan Ruang Lingkupnya. Jakarta: Prisma.

Siti Muhajiroh Widiyati. 2010. Potensi Pajak Restoran dan Pajak Parkir Terhadap Pendapatan Asli Daerah (PAD) Kabupaten Boyolali. Fakultas Ekonomi Universitas Sebelas Maret Surakarta.

Soemarso. 2009. Akuntansi Suatu Pengantar, Buku ke 2, Edisi 5. Jakarta: Selemba Empat.

Suandy, Early. 2011. Hukum Pajak. Jakarta Selatan: Salemba Empat.

Subakti, Carolina Christine. 2011. Peramalan Sumber-Sumber Earmarking Penerimaan Daerah (Studi Kasus: Pembiayaan Pemeliharaan Jalan Kota di Kota Bandung). Bandung: Bank Mandiri. 
Triski Intan Meylani Lengkong, Ventje Ilat, Anneke Wangkar. 2015. Analisis Potensi dan Efektivitas Pemungutan Pajak Reklame di Kota Bitung. Fakultas Ekonomi dan Bisnis Universitas Sam Ratulangi Manado.

Ulfa Mega Kristianti. 2017. Efektivitas Pajak Hotel, Efektivitas Pajak Restoran, Kontribusi Pajak Hotel, Kontribusi Pajak Restoran Terhadap Pendapatan Asli Daerah Kabupaten Nganjuk Tahun 2013-2016. Fakultas Ekonomi Universitas Nusantara PGRI Kediri. . Undang-undang Nomor 28 Tahun 2007 tentang Ketentuan Umum dan Tata Cara Perpajakan. . Undang-Undang Nomor 28 Tahun 2009 tentang Pajak Daerah dan Retribusi Daerah. . Undang-undnag Nomor 32 Tahun 2004 tentang Pemerintahan Daerah. . Peraturan Pemerintah Nomor 65 Tahun 2001 tentang Pajak Daerah. . Peraturan Daerah Kota Tomohon Nomor 7 Tahun 2012 tentang Pajak Daerah. 